\title{
Analysis on Cross-cultural Competence and the Demands for Compound International Business Talents
}

\author{
Xiaoyan Zhou \\ Xi'an International University, Xi'an, Shaanxi, 710077
}

\begin{abstract}
Keywords: Compound International Business Talents, Cross Cultural Competence
\end{abstract}
\begin{abstract}
Cultivating the intercultural ability of international business talents is the realistic demands of Chinese enterprises in the new stage, and also the reasonable demands of cultivating innovative talents in higher finance and economics colleges and universities. Intercultural competence is the core professional quality of international business professionals, and should pay attention to its unique role in the formation of professional quality. As the main body of personnel training, colleges and universities should actively explore and cultivate the level of cross - cultural ability training of international business professionals in the aspects of curriculum system construction, talent quality standard, practice teaching, international campus culture construction and student entrepreneurship.
\end{abstract}

\section{Introduction}

With the globalization of trade and the development of liberalization, multinational companies, both in quantity and scale, are rapidly expanding. The new international trade situation requires that business members must have sufficient cross-cultural capacity, which is the new reality to promote the Chinese enterprises to the world's real needs. The rise of intercultural management began at the end of the last century and was initially developed in Europe and the United States. With the development of economy, the trend of economic globalization has intensified, and the phenomenon of multinational operation has been gradually popularized. For the research of cross-cultural field, the business schools in Europe and the United States have paid great attention to the cross-cultural ability of students to cultivate. In contrast, China's international development of enterprises started late, for cross-cultural research is also relatively backward, however, more and more enterprises and universities are now aware of its importance. For international business professionals, cross-cultural competence is the core professional quality, we must pay attention to it. As the main body of personnel training, colleges and universities must strengthen the cultivation of cross-cultural ability of international business talents under the new normal background.

\section{The Connotation of Intercultural Competence of International Business Talents}

The dimensions of intercultural competence of international business talents mainly include the following three aspects: one is cross-cultural cognition, two is cross-cultural motive and three is cross-cultural behavior. Among them, the cross-cultural cognitive elements include: cross-cultural background of cognitive flexibility, attribution reasoning, judgments and decision-making. All of these elements work are together to influence the individual's cultural abilities, such as knowledge and handling of individual statements, procedural and conditional issues. Narrative knowledge and international trade and cross-border management and other areas associated with procedural knowledge refer to a specific international business tasks in the process of dealing with the behavior and manner. Cross-cultural motivation refers to the cross-cultural background, the individual's goal setting and self-efficacy, etc., to cross-cultural resonance and the formation of incentives to different cultures to understand and receive, to help individuals in the cross-cultural background Stable attitude, to enhance their ability to adapt to promote the individual to meet the psychological generation. Cross-cultural behavior refers to the individual's self-representation in the context of cross-cultural, language communication, which is the result of the interaction of the two cross-cultural dimensions. The quality of the cross-cultural behavior of the individual after the 
upgrade, the face of different goals, context and language or non-verbal behavior will be more effective. At the same time, the promotion of cross-cultural behavior is also conducive to the elimination of cultural bias, etc., to enhance the success rate of international business.

\section{New Norms on the Intercultural Competence of International Business Talents}

First, the new normal, the international business talent must give full play to the role of cultural exchanges and cooperation, promote the common development of different civilizations, pay attention to the role of cultural communication, enhance the sense of responsibility, establish a good image of the domestic enterprises in the international China and the "one side along the way" along the common development of countries to enhance cooperation in the inclusive, pay attention to economic efficiency, environmental protection and social equity maintenance, and promote the sustainable development of international trade.

Second, similar to domestic trade exchanges and international trade is also prone to some disputes. However, unlike domestic trade, the culture and habits of international consumers are different, and there is a certain degree of particularity. If there is a trade dispute, the consumer's resistance and disagreement will be more obvious. Therefore, enterprises engaged in international trade must be flexible use of various communication skills and expression, to the different consumers in the international interpretation of the problem, and actively collect from different regions and countries, the establishment of information communication mechanism. Enterprises engaged in international trade in order to obtain long-term development in overseas markets, to win the trust of overseas consumers must be product quality to conquer consumers, from product development, sales and other aspects of strengthening management, improve the international business talent construction, the role of cultural exchange.

Thirdly, at present, China's foreign trade enterprises face the challenge of fragmentation from the free trade zone and the low level of the FTA. In order to promote the FTA strategy in our country, we must focus on accelerating regional integration in the Asia-Pacific region, Of the free trade mechanism to make reasonable arrangements, so as to continuously reduce transaction costs and promote the success of international trade. And strive to promote the global high standards of free trade zone network formation, which can be in the future development of trade rules have more right to speak.

\section{The Cultivate Path for International Business Talent Cross-cultural Ability}

The practice and experience of international business show that practitioners' good cross-cultural motives, perfect cross-cultural cognition and decent cross-cultural behavior are the key to the successful implementation of the strategy of cross-border electricity and FTA. Talent training to market demand-oriented. At present, the international business talent training model is only concerned about the cultivation of professional ability, cross-cultural ability to be ignored, to reverse this situation, the need to strengthen cross-cultural capacity from the following path.

Intercultural competence of international business people is an important factor restricting the success of international business. To strengthen the construction of international business personnel and cross-cultural ability training, we must first pay attention to the top design of personnel training mechanism, through scientific research and development of international business personnel recruitment and selection criteria. What kind of talent to be competent for international business activities, the past has been the lack of scientific standards, the lack of scientific indicators to provide the basis for evaluation, there is no matching recruitment and selection methods, cross-cultural skills for practitioners without scientific training methods, recruitment only focus on professional skills And foreign language skills, cross-cultural ability to be ignored. To this end, the government should increase investment in scientific research to promote cross-cultural capacity of the relevant research, to build cross-cultural ability index system, evaluation methods, selection criteria, training mechanism four-in-one research training mechanism to ensure cross-cultural ability to implement the talent Evaluation, selection, training of all links. 
At this stage, China should strengthen the understanding of overseas international business personnel qualification examination and certification standards, study the introduction of foreign international business examinations and certification of the introduction of planning to accelerate the internationalization of personnel training standards. In view of this, the Ministry of Education, the Ministry of Commerce, the Ministry of Personnel and other relevant departments should be in the joint supervision, unified standards, under the premise of correct guidance, as soon as possible to establish international business practice mutual recognition of the coordination mechanism to promote international business personnel certification standards of internationalization. Government departments should increase investment in education, to take preferential policies to encourage well-known foreign institutions to domestic cooperation in running schools.

Developed countries such as the United States and other well-known university business school student training program generally includes four modules: international business courses (international trade, international finance, international investment, international marketing, multinational management, international economic law, WTO regulations, international accounting, etc.), How to improve the performance of the workplace, efficient administration, business ethics, business and marketing, regional business, efficient sales, information management, and so on. ), Cross-cultural competence modules (cross-cultural business communication, cross-cultural business negotiations, international business etiquette, cross-cultural psychology, business correspondence, regional political economy, regional culture courses), foreign language courses (listening, speaking, Translation, etc.), plus overseas internship or study for one year. The research paradigm of American Business School provides us with reference: the compound degree of cross-cultural ability (specialized course, general education course and foreign language) should be strengthened in our university science curriculum, and the training mode of innovative talents should be strengthened, and international business practice should be established in close cooperation with multinational corporations Platform to strengthen the cross-cultural experience of international business professionals.

International enterprises should be broaden the channels of random selection of talent. International enterprises regardless of size, in the international business recruitment and selection process should abandon the traditional geographical concept, family concept and human feelings, broaden the scope of selection, talent decision-making to increase the introduction of foreign talent, the introduction of the introduction strategy; Attention to the cultivation of their own talent, the implementation of going out strategy. For example, with the well-known university business school, the allocation of special funds for commissioned training, overseas dispatch to learn, to attract returnees and other talents, to attract cross-cultural ability level, professional and strong integration of international business professionals to join the international business Fresh blood. The process of recruitment and selection should comprehensively examine the level of cross-cultural awareness and behavior to meet the new challenges of international business and new business development needs. At the same time, enterprises need to create a learning atmosphere, to promote international business people in their careers continue to improve the level of cross-cultural ability.

In the reform of teaching methods, we must ensure that the development of new knowledge on the basis of the existing knowledge of students to start, but also and students of language communication practice combined. Pay attention to the differences between Chinese and Western culture, teaching in the cultural factors if the impact of teaching progress, to carry out the necessary cultural explanation. Attention to step by step, the focus of teaching on the ability of students in the training, to enhance their use of cross-cultural knowledge to solve the problem. In daily learning, teachers should guide students to look at the Western countries, social and cultural, lifestyle, ideology and economic and trade aspects of the books, so that students of the target country's culture can have a comprehensive understanding. In addition, in order to meet the curiosity of students and cross-cultural ability requirements, you can also organize a number of seminars to attract students' attention in order to take the initiative to complete the exploration of knowledge. 


\section{Conclusion}

As the core competence of international business talents, cross-cultural ability has a wide application prospect and huge practical needs in many fields such as business and culture. College personnel training must pay close attention to the development of the market and formulate the detailed index system of professional talents ability. Personnel training programs and international standards of the curriculum system to create an international campus culture, well-designed practice teaching and professional trainee mechanism, attention to personnel training in the normative and practical, with effective system of protection and mechanism to ensure that students cross-cultural capacity The comprehensive improvement of professional competence and the formation of international business comprehensive quality.

\section{Acknowledgements}

Fund Project: Shaanxi Province Education Science "13th Five Year Plan" 2016: "Silk Road Economic Zone" strategy under the complex international business personnel training model research;

No.: SGH16H289.

\section{References}

[1] Wang Yuhang. International business professionals in cross-cultural ability training [J]. International Business, 2015 (04)

[2] Xiao Fen, Tang Haili Li. National Path of Cultivating Intercultural Competence of International Business Talents under New Normal Situation [J] .Journal of Learning and Practice, 2015 (06)

[3] Wang Jun. Sino-British cooperative education based on CDIO international business professionals cross-cultural ability training [J]. Technology and Economic Journal, 2016 (03)

[4] Zhang Xuehui. College Students cross-cultural ability training mode construction [J]. Contemporary teaching and research series, 2017 (01)

[5] Li Yiming, Li Zhuoni. Study on the influence of individual traits on college students' intercultural competence [J]. Journal of Heilongjiang Province Political Science and Law Institute, 2016 (03) 